\title{
What Providers and Medicaid Policymakers Need to Know About Barriers to Employment for People with Disabilities
}

\author{
Jean P. Hall, PhD \\ Michael H. Fox, ScD
}

\begin{abstract}
Medicaid Buy-Ins provide a new and exciting opportunity for people with disabilities to engage in meaningful employment while maintaining Medicaid coverage. Through interviews with participants in the Kansas Medicaid Buy-In, we examined perceived external influences on the decision to acquire or increase employment by people with disabilities. Two major external barriers were identified. First, physicians, therapists and case workers had frequently discouraged participants from getting jobs or increasing employment levels. Difficulty accessing adequate and consistent medical care and/or medications through Medicaid was also an issue in preventing participants from being able to acquire or increase employment. [Article copies available for a fee from The Haworth Document Delivery Service: 1-800-HAWORTH. E-mail address: <docdelivery@haworthpress.com> Website: <http://www.HaworthPress.com> (C) 2004 by The Haworth Press, Inc. All rights reserved.]
\end{abstract}

Jean P. Hall is Assistant Research Professor at the University of Kansas Center for Research on Learning, Division of Adult Studies, 1122 West Campus Road, Room 517, Lawrence, KS 66045-3101.

Michael H. Fox is Associate Professor in the Department of Health Policy and Management, University of Kansas Medical Center, 3901 Rainbow Boulevard, Kansas City, KS 66160.

This research was funded in part through a contract with the Kansas Department of Social and Rehabilitation Services.

Journal of Health \& Social Policy, Vol. 19(3) 2004

http://www.haworthpress.com/web/JHSP

(C) 2004 by The Haworth Press, Inc. All rights reserved.

Digital Object Identifier: 10.1300/J045v19n03_03 
KEYWORDS. Medicaid Buy-In, disability, work incentives, employment

\section{INTRODUCTION: MEDICAID, WORK AND PEOPLE WITH DISABILITIES}

Currently, less than one half of one percent of people with disabilities who receive Supplemental Security Income (SSI) or Social Security Disability Insurance (SSDI) ever returns to work (U.S. House Committee on Commerce 1999; U.S. Senate Finance Committee 1999). The number of people with disabilities receiving these benefits-and their allied health care programs, Medicaid and Medicare-has steadily increased, more than doubling from 4 million in 1985 to more than 9.1 million in 2000 (Perry 1999; Social Security Administration [SSA] 2000). Recognizing that some federal policies served as disincentives for these individuals to return to work, Congress passed the Ticket to Work and Work Incentives Improvement Act in 1999 (TW-WIIA; Public Law 106-170).

The provisions of TW-WIIA are designed to address what policymakers perceive to be major barriers to employment for people with disabilities-namely, loss of public health care coverage and lack of disability-responsive employment services. Such perceptions are well founded in disability policy literature (e.g., National Council on Disability 1997; President's Task Force on Employment of Adults with Disabilities 1998). Unquestionably, people with disabilities have substantially higher health care costs and lower employment rates than people without disabilities. Max, Rice and Trupin (1996) estimated that health care costs for people with disabilities across the life span are more than four times as much as for those without disabilities while Stapleton, Livermore, Scrivner and Tucker (1997) estimated the differential to be more than seven times as much for non-elderly $(<65$ years old) people with disabilities. The National Organization on Disability/Harris 2000 Survey of Americans with Disabilities found that, among working-age adults with disabilities (ages 18-64), three out of ten (32\%) were working full-time or part-time, compared with eight out of ten (81\%) of those without disabilities (National Organization on Disability [NOD] 2000). Furthermore, the findings from the poll suggested that the proportion of working-age adults with disabilities has actually declined since 1986, when $34 \%$ were working. These figures are even more disturbing in light of the fact that the great majority $(>70 \%)$ of those not working said they wanted to work (NOD 2000; Stoddard, Jans, Ripple \& Kraus 1998). 
TW-WIIA has two major provisions. The first part of the law addresses employment supports for people with disabilities through the "Ticket to Work and Self-Sufficiency," a voucher program that gives SSI recipients and SSDI beneficiaries a "ticket" to receive intensive rehabilitation and employment services at no cost. The second part of the law addresses continued access to public health insurance. Because Medicaid is a means-tested program, people with disabilities who have chosen to work in the past have generally lost their eligibility for Medicaid coverage. TW-WWIA gives states the option and provides incentive grants (Medicaid Infrastructure Change grants) to create a program for SSI and SSDI beneficiaries who engage in gainful employment to get or retain Medicaid coverage. States have the option of using these grants to raise the income limits for Medicaid eligibility, disregard some earned and unearned income, raise asset limits, exempt certain assets, and charge premiums on a sliding scale in extending the availability of Medicaid coverage to people with disabilities who work.

Studies conducted after the implementation of Medicaid Buy-In programs under TW-WIIA identified additional barriers to employment including: loss of cash benefits for SSDI beneficiaries who earned above $\$ 800$ per month; lack of adequate transportation, childcare and housing; lack of education; lack of work history; and lack of placement services (e.g., Hanes, Edlund \& Maher 2002; Jensen, Silverstein, Folkemer \& Straw 2002). As part of an evaluation of the Kansas Medicaid Buy-In program, called "Working Healthy," the authors interviewed people with a variety of disabilities to ask about their perceived barriers to work.

\section{STUDY DESIGN AND DATA COLLECTION}

The methodology used for our research follows the case study design described by Yin (1994). We utilized a group meeting followed by focused individual interviews using both representative (across various disabilities, ages, educational levels, rural, suburban and urban areas, and gender) and convenience (within a 2-hour drive of Lawrence, KS) sampling to select participants.

\section{The Sample}

In early summer 2002, the Oregon Health Policy Institute (OHPI) requested assistance from the authors in setting up a cross-disability focus 
group to discuss issues related to health care, disability, and employment barriers as part of their study of work incentives programs. We used the list of potential Working Healthy enrollees as a pool for selecting focus group participants. A list of 46 people representing a range of disabilities and living within a 2-hour drive of the focus group site (Lawrence, KS) was generated as potential participants. A letter was sent on June 28 to this group inviting them to participate and explaining that OHPI would reimburse them for mileage and provide a \$25 WalMart gift card to each participant. Nine people representing a range of disabilities (psychiatric, physical, chronic illness, cognitive, and sensory) attended, along with one spouse who also had a disability.

Because the Working Healthy program was implemented on July 1, 2002, transcripts from the focus group served as a background piece in understanding the status of specific individuals at baseline. The focus group participants all indicated a willingness to be interviewed individually by the authors about six months after the July meeting.

Six of the nine original participants were enrolled in Working Healthy by November 2002. In mid-November, we contacted these six individuals plus an additional two enrollees from Lawrence to ask them to participate in in-depth interviews about their experiences with the Working Healthy program and any changes in their lives subsequent to their enrollment.

\section{The Interviews}

All eight individuals agreed to participate and the interviews were conducted at various sites between December 2 and 11, 2002. Information about each of the eight participants is summarized in Table 1. Each interview was audio-taped and participants received a \$20 cash stipend.

The questions for the interviews were developed based on issues raised in the initial Kansas focus group and by other program evaluation and review efforts such as those by Hanes et al. (2002) and Jensen et al. (2002). Several of the questions specifically addressed how policy issues within the Kansas Buy-In program and the federal Social Security program influenced participants' work efforts. Additional questions addressed external factors that may affect an individual's decision and/or ability to work more, including availability of adequate medical care/ medications, physician support, and effective support programs. The interviews focused on participants' work, benefits, and health care experiences before and after enrolling in Working Healthy, but participants were also encouraged to provide any feedback about the program, their 
TABLE 1. Summary Information on Interview Participants

\begin{tabular}{|c|c|c|c|c|c|c|}
\hline Person & Age & Disability 1 & Disability 2 & Disability 3 & Race & $\begin{array}{c}\text { Current } \\
\text { educational level }\end{array}$ \\
\hline Diane $^{a}$ & 41 & Depression & $\begin{array}{l}\text { Borderline personality } \\
\text { disorder }\end{array}$ & - & White & Four year degree \\
\hline $\operatorname{Rob}^{\mathrm{a}}$ & 33 & $\begin{array}{l}\text { Schizo-affective } \\
\text { disorder }\end{array}$ & - & - & White & Some college \\
\hline$J^{\prime} u l i e^{a}$ & 49 & Depression & $\begin{array}{l}\text { Post-traumatic stress } \\
\text { disorder }\end{array}$ & Bipolar disorder & White & Some college \\
\hline Pamela & 41 & Cerebral palsy & Spinal injury & - & White & High school or GED \\
\hline Ben & 31 & Learning disability & Mental retardation & Anxiety disorder & White & High school or GED \\
\hline Marilyn $^{a}$ & 36 & Depression & Bipolar disorder & Obesity & White & Two year degree \\
\hline Martha ${ }^{a}$ & 40 & $\begin{array}{l}\text { Social phobia } \\
\text { disorder }\end{array}$ & Bipolar disorder & Depression & White & Graduate degree \\
\hline Daniel $^{a}$ & 47 & $\begin{array}{c}\text { Traumatic brain } \\
\text { injury }\end{array}$ & Mental illness & - & $\begin{array}{l}\text { Native } \\
\text { American }\end{array}$ & Some college \\
\hline
\end{tabular}

Note: All disabilities are self-reported.

${ }^{a}$ This person participated in the OHPI focus group 
employment, their quality of life or any other topic they felt to be relevant. All of the interview participants were asked questions about:

1. Changes in their work effort or earnings since enrolling in Working Healthy;

2. Whether they had had a spenddown prior to enrollment;

3. Whether their decision to increase earnings or work efforts (if applicable) was influenced by the potential loss of cash benefits;

4. Whether they felt they were receiving adequate medical care and had access to the medications they needed; and

5. Whether their doctor(s) or other medical professionals were supportive of their decision to work and/or of their level of work.

\section{Analysis}

Transcripts were made for each interview and checked for reliability by two researchers. The transcripts and notes from the consumer interviews were next used to develop a case study for each individual. The case study evidence was then examined, categorized and tabulated with the goal of identifying recurring themes or "pattern-matching" (Yin 1994). By using multiple case studies to verify themes, we hoped to address the issue of external validity. The case studies in combination with corroborating themes from the focus group transcript allowed for triangulation of data and, consequently, provided construct validity for the findings.

\section{RESULTS}

A variety of themes emerged from the data. These themes can be summarized as follows:

- Working Healthy is a good idea and a good program

- Participants felt relief in having lost their spenddown obligations

- Employment is a desirable goal and people have a responsibility to work

- The potential loss of benefits due to increased earnings was not a concern to most participants because their current income level was quite low

- A person's disability is often a barrier to work, but external service and policy barriers are overarching 
Of these themes, the existence of service and policy barriers to work seemed to be of most concern to participants. Additionally, these barriers are ones that can be addressed by readily achievable changes in knowledge, practice, and policy. Specifically, the two major service and policy barriers to work that emerged from the interviews were negative advice from health and allied service professionals about working and the inadequacy of Medicaid in meeting the needs of program participants.

\section{Negative Advice from Service Providers}

Five of the eight interview participants related that their physicians or allied health service providers had advised them not to work or not to increase their current work efforts. The reasons for this advice varied. In several instances, the providers believed that working more would be detrimental to their client's or patient's health in spite of the participants' expressed belief that they could work more and desired to do so. Marilyn related "my doctor, my therapist, my case manager, all these people say don't try to do any more. Part of me says I'm ready to take on a little more, but they say "you' re not ready to." Similarly, Diane shared that "I would like to work more, but I don't. They're saying to take it slow [her physicians], so I'm going by their advice because they are my treaters, they do know me and they said to take it slow at first."

Martha's experience was more extreme in that her providers advised against her working at all and actually prevented her from getting help in finding a job. Martha had contacted the state Vocational Rehabilitation (VR) program because she wanted to work. Martha recounted that "She [the vocational rehabilitation counselor] called my therapist and she said 'no way is she ready for a job' and the lady said 'you know, your therapist said there is no way that you can do it' and she was really sweet but she said that 'you know if your therapist is saying that, there is no way that I am going to try to put you through something that you are going to end up not being able to handle.'" Martha ended up finding her own job through word of mouth and has maintained it for more than a year.

Other providers advised against work or increased work efforts because of their often misguided beliefs that increased work would adversely impact their client's or patient's Social Security, health care, or other benefits. Rob said his psychiatrist "was glad to hear that I am still working under my benefits." Ben shared that his case manager at the local community developmental disability organization told him he would 
"lose it all" (his benefits) if he worked too much. Marilyn explained her experience with this mindset:

I was actually discouraged by my case manager from going to work initially when I wanted to work. She said, "you're eligible for energy assistance in the winter, you're eligible for commodities, you're eligible for . .." and she started listing things that I never had done. She said, "you'll lose all those things and you won't make that much money" and so she kind of discouraged me from working.

\section{Inadequacies of Medicaid Coverage}

Six of the eight participants cited inadequacies of their Medicaid coverage as a barrier to work readiness and/or work retention. Prior to their enrollment in Working Healthy, all of the interview participants had qualified for Medicaid only through the state's medically needy program. Such programs require participants to "spend down" their income to the state's medically needy income limit (MNIL), which was \$475/ month in Kansas in 2002 (thirty-five states and the District of Columbia currently operate medically needy programs). As Crowley (2003) noted, "the opportunity to spend down is particularly important to adults with disabilities who incur high prescription drug, medical equipment, or other health care expenses."

Due to the sporadic nature of their Medicaid coverage through the medically needy program, five of the interview participants reported having had difficulty in getting prescription medications prior to enrolling in Working Healthy. Rob and Ben both told us they had amassed large pharmacy debts that they were still paying off half a year later. Marilyn, whose prescription drug costs average $\$ 900 /$ month shared the following:

I really thought the spenddown process was just ridiculous because I had this huge amount and, actually, if I didn't work in a pharmacy where my boss would let me charge all the medicines until I came up with the spenddown amount, there was no way I could make this work. It was just a ridiculous situation and having it just kind of balloon on me every six months seemed really crazy.

Martha also had difficulty getting medications while on the medically needy program: 
I would get Medicaid the last two months of the six months, which pays for my prescriptions except a couple of dollars. So that was tough because four months I was paying for my prescriptions and only two months out of the six was my medication being paid for, and my medications are not cheap.

Julie's story gets to the heart of the problem and illustrates how inadequate coverage made it difficult for her to attain the level of health she needed to be able to work. She said, "I didn't take my medication [while in her spenddown period]. I couldn't afford it, that's why I am where I am right now [in a worsened mental condition]."

Two of the participants with mental illness also shared stories of not being able to find providers who accept Medicaid payment. Marilyn told us, "I had to switch to see the psychiatrists through the county mental health center because I was having a hard time finding an outpatient psychiatrist that would take Medicaid." She also related a bad experience with a six-day hospitalization. She found out, well after the fact, that the psychiatrist assigned to her at the hospital did not accept Medicaid. She said she had to "scrounge" to come up with the very unexpected out-of-pocket expenses. Martha was ultimately unable to find a mental health provider who accepts Medicaid: she currently sees a psychiatrist and a therapist for whom her privately-purchased insurance pays "eighty percent, most of the time."

Finally, three of the participants noted that lack of coverage for dental services by Medicaid could have the effect of hindering a person's ability to get or keep a job. Pamela explained, "dental care is expensive. I can't afford it and Medicare doesn't help cover it at all." Julie elaborated, "if you really think about it, if you have a severe toothache and you can't get it taken care of, you're not going to go to work, right?" Marilyn added her perspective as an employee at a pharmacy: "we see people who end up spending a lot of money on antibiotics because they end up getting terrible infections [due to inadequate dental care]." She said that she would be happy to pay an extra ten dollars a month in premiums to get dental coverage through Working Healthy.

\section{DISCUSSION}

All of the interview participants, regardless of the type or severity of their disabilities, expressed a strong desire to work and, indeed, their obligation to society to do so. The main barriers to work they cited were 
external in nature and included negative advice from service providers and difficulty accessing adequate medical services.

\section{Outreach to Service Providers}

Persons who apply for Social Security benefits must undergo a rigorous disability determination process and must often appeal initial rulings against their eligibility. Part of this process involves getting documentation from physicians, therapists or other service providers that one is "too disabled" to work. A negative consequence of this system is that medical or other service providers, wary of having to provide even more documentation and mindful of the difficulty of obtaining benefits, may take a paternalistic attitude when their patients or clients broach the subject of working. In Kansas, service providers had in many cases discouraged the interview participants from getting jobs or increasing employment levels due to the often misguided belief that doing so would jeopardize their benefits or automatically result in a worsening of their patient's or client's condition. The Ticket to Work and Work Incentives Improvement Act includes provisions that allow people on Social Security Disability who work to maintain premium-free Medicare coverage and gives states the options to extend Medicaid coverage to disabled workers. Because this law represents a major paradigm shift, service providers need to be provided with updated information about new opportunities for their patients or clients. In addition, disability advocates may need to extend their outreach to these providers to explain how job accommodations can make work a realistic and positive outcome for people with disabilities. For example, many providers are probably not aware that the Americans with Disabilities Act includes in its definition of "reasonable accommodations" job restructuring, modified work schedules (including part-time work or more frequent breaks), and modified work environments or equipment (such as a corner cubicle or provision of ergonomic furniture). With adequate workplace supports, the great majority of people with disabilities can engage in meaningful employment without jeopardizing their health.

\section{Changes to Medicaid}

Many interview participants shared that they were not consistently able to get needed services or medications through Medicaid, often because of the way in which the spenddown process works, making them eligible for coverage for only a few months at a time. Others had difficulty 
finding providers who accepted Medicaid. This study underscores the fact that many people with disabilities need more and better access to specialists and prescription drugs. Crowley (2003) documented that very little information is reported about the characteristics of medically needy populations and that "little data are available to evaluate how well Medicaid is meeting their health care needs." For the individuals in this study, Medicaid was consistently failing to meet their needs.

Crowley (2003) cites data indicating that medically needy people with disabilities had average per capita Medicaid costs of $\$ 17,283$ versus a per capita cost of $\$ 9,212$ for categorically eligible people with disabilities in FY 2000. In contrast, per capita costs for medically needy children and parents were similar to their categorically eligible counterparts. Given that the medically needy population of people with disabilities may only be eligible for Medicaid coverage for several months out of each year, the difference in their spending is even more notable. One cause for the increased expenses may be the nature of the program itself. By having only sporadic coverage, medically needy individuals with disabilities do not consistently get the medications and treatment that they need. Consequently, by the time they are able to access Medicaid services, their conditions may be drastically worse and more expensive to treat.

Kansas uses a six-month period to calculate spenddown amounts. Thus, if a person's income after disregards averages $\$ 200$ per month more than $\$ 475$, his or her 6-month spenddown amount is $\$ 1200$. Disregards include the first $\$ 20$ of unearned income and a portion of earned income. Once the spenddown amount is "met" through medical expenses at the beginning of a six-month period, the person is eligible for Medicaid coverage on all other medical expenses incurred during the remainder of the period. A new spenddown amount is then calculated for the next 6-month period and so on. Obviously, the spenddown requirement can be a disincentive to working, because additional income only results in a larger spenddown amount.

In the context of this study, Medicaid Buy-In programs are therefore especially beneficial to people with disabilities who otherwise qualify for Medicaid only through a spenddown process. The Buy-In allows these individuals who work the opportunity to have year-round Medicaid coverage with a premium based on their income level. For the people interviewed in this study, their premium-if they had one at all-was always less than their spenddown obligation had been. Thus, working is not only a reasonable goal, but also a very desirable one for these people 
who can gain consistent access to Medicaid services by enrolling in the Buy-In.

In its study of 12 states' early experiences with Medicaid Buy-Ins under TW-WIIA, the U.S. General Accounting Office (2003) documented that, of the 11 Buy-In states with medically needy programs, all but one had MNILs well below the federal poverty level of $\$ 8,860$ per year for 2002. Indeed, in Arkansas, an individual must spend down to an annual income of just $\$ 1300$ per year to qualify for Medicaid coverage. That same individual would be left with less than $\$ 110$ per month after outof-pocket medical expenses to cover his or her housing, clothing, food and other personal costs.

States have two options to increase access to Medicaid for people with disabilities under their medically needy programs: they can increase their MNIL or they can disregard more of the income counted against the MNIL. States' MNILs are tied to the amount of cash assistance paid to families on the state's welfare program, and cannot be more than $133 \%$ of that amount (Centers for Medicare and Medicaid Services [CMS] 2002). Data collected by the National Association of State Medicaid Directors (NASMD 2002) indicate that only 8 states have increased their MNILs since 2001 and 18 states have not adjusted them since 1994 or before. In Kansas, the MNIL has not been adjusted for an individual since 1997 and for a couple since 1994. The great majority of states with medically needy programs have no mechanism in place to regularly adjust their MNILs. In essence, then, the MNIL as a percentage of poverty level has decreased over time, making it more difficult to achieve through a spenddown process for people who need it and leaving them very little income upon which to live.

States have considerably more flexibility in how much income they disregard in calculating whether a person meets the MNIL. In a series of letters to State Medicaid Directors, the Health Care Financing Administration (HCFA 2001) outlined a number of ways that states could fulfill their obligations under the Americans with Disabilities Act to empower more people with disabilities to live in their communities rather than being forced into institutions. HCFA encouraged states to use authority under section 1902(r)(2) of the Social Security Act to disregard greater amounts of earned and/or unearned income under their medically needy programs, effectively reducing the large spenddown liability for many people with disabilities and making Medicaid coverage more consistently available to a larger portion of this population (the disregards can be targeted to specific medically needy eligibility groups, such as only those with disabilities). Despite the flexibility afforded by this option, 
21 states do not apply it in disregarding any income for their medically needy programs and others disregard only small amounts of income (NASMD 2002).

In the larger context of Medicaid policy, this study demonstrates that many people with disabilities may not be well served by medically needy programs. Moreover, their costs to the states and federal government are actually higher, at least in part because coverage is not consistent. Though this finding may be counter-intuitive, i.e., if they are not eligible for Medicaid all the time, their overall costs should be less, it is nevertheless borne out by the data. People with disabilities make up only $15 \%$ of the medically needy population, but account for $38 \%$ of its spending (CMS 2003).

In their review of the Maryland High-Cost Patient Project, Stuart and Weinrich (1998) found that thirty percent of high-cost Medicaid patients (those whose annual expenditures fell in the top 10\%) were those not continuously enrolled in the program. They reported "providers express particular concern about patients who cycle on and off Medicaid because they are unable to pay for preventive care." In response to the disproportionately higher costs of Medicaid eligibles with disabilities, the state of Maryland instituted an intensive case management system called the Maryland High Cost User Initiative, which generated substantial savings in health care spending for Medicaid enrollees with disabilities. Under such a program, people with disabilities receive assistance in finding the physicians, services and medications they need. Accordingly, states with Medicaid buy-ins should consider taking other similar approaches to meet the oftentimes complex health care needs of people with disabilities-especially those with inconsistent access to care. In doing so, they may increase the numbers of these people who are ready-physically and mentally-to enter the workforce.

\section{REFERENCES}

Centers for Medicare and Medicaid Services. (2003). Medicaid Statistical Information System Statistical Reports for Federal Fiscal Year 2000. Washington, DC: Author.

Centers for Medicare and Medicaid Services. (2002). State Medicaid Manual. Retrieved October 17, 2003, from http://www.cms.hhs.gov/manuals/45_smm/pub45toc.asp.

Crowley, J. (2003). Medicaid medically needy programs: An important source of Medicaid Coverage. Kaiser Commission on Medicaid and the Uninsured Issue Paper. Washington, DC: The Henry J. Kaiser Foundation.

General Accounting Office. (2003). Medicaid and Ticket to Work: States' Early Efforts to Cover Working Individuals with Disabilities. GAO-03-587. Author. 
Hanes, P., Edlund, C., \& Maher, A. (2002). Three-state work incentives initiative: Oregon, Vermont, and Wisconsin. Portland, OR: Oregon Health Policy Institute.

Health Care Financing Administration (HCFA). (2001). Olmstead Update No. 5. Retrieved October 16, 2003, from www.cms.hhs.gov/states/letters/smd110a1.pdf.

Jensen, A., Silverstein, R., Folkemer, D., \& Straw, T. (2002). Policy frameworks for designing Medicaid Buy-In programs and related state work incentive initiatives. Washington, DC: Office of Disability, Aging and Long-Term Care Policy.

Max, W., Rice, D.P., \& Trupin, L. (1996). Disability Statistics Abstract, 12. Washington, DC: U.S. Department of Education, National Institute on Disability and Rehabilitation Research.

National Association of Medicaid Directors. (2002). Aged, Blind and Disabled State Summaries. Retrieved October 17, 2003, from http://www.nasmd.org/eligibility.

National Council on Disability (NCD). (1997). Removing barriers to work: Action proposal for the 105th Congress and beyond. Retrieved September 24, 2002, from http://www.ncd.gov/newsroom/publications/barriers.html.

National Organization on Disability. (2000). 2000 N.O.D./Harris survey of Americans with disabilities. Washington, DC: Author.

Perry, A. (1999). Social Security work incentive reform. What is it? Why is it needed? Issue Brief in Independent Living and Disability Policy, 1(3): 1-9. Oakland, CA: World Institute on Disability.

Presidential Task Force on Employment of Adults with Disabilities. (1998). Re-charting the course: First report of the Presidential Task Force on Employment of Adults with Disabilities. Washington, DC: Author.

Social Security Administration, Office of Policy, Office of Research, Evaluation, and Statistics. (2000). Fast facts and figures about Social Security. Washington, DC: Author.

Stapleton, D., Livermore, G., Scrivner, S., \& Tucker, A. (1997). Exploratory study of health care coverage and employment of people with disabilities: Literature review. Washington, DC: Office of Disability, Aging and Long-Term Care Policy.

Stoddard, S., Jans, L., Ripple, J., \& Kraus, L. (1998). Chartbook on work and disability in the United States, 1998. Washington, DC: U.S. National Institute on Disability and Rehabilitation Research.

Stuart, M.E. \& Weinrich, M. (1998). Beyond managing Medicaid costs: Restructuring care. The Milbank Quarterly, 76(2): 251-280.

Ticket to Work and Work Incentives Improvement Act of 1999, Pub. L. 106-170.

U.S. House Committee on Commerce. (March 23, 1999). Hearing on H.R. 1180, The Work Incentives Improvement Act of 1999. Report 106-15. 106th Congress, 1st Session.

U.S. Senate Finance Committee. (March 26, 1999). Report on S. 331, The Work Incentives Improvement Act. Report 106-37. 106th Congress, 1st Session.

Yin, R.K. (1994). Case study research: Design and methods (2nd ed.). Thousand Oaks, CA: Sage Publications. 
Copyright of Journal of Health \& Social Policy is the property of Haworth Press and its content may not be copied or emailed to multiple sites or posted to a listserv without the copyright holder's express written permission. However, users may print, download, or email articles for individual use. 